\title{
US respondents' willingness to pay for Cheddar cheese from dairy cattle with different pasture access, antibiotic use, and dehorning practices
}

\author{
Courtney Bir, ${ }^{1 *}$ ๑ Nicole Olynk Widmar, ${ }^{1} \oplus$ Nathanael M. Thompson, ${ }^{1} \oplus$ Jonathan Townsend, ${ }^{2} \odot$ \\ and Christopher A. Wolf ${ }^{3}$ (i) \\ ${ }^{1}$ Department of Agricultural Economics, Purdue University, West Lafayette, IN 47907 \\ ${ }^{2}$ Department of Veterinary Clinical Sciences, Purdue University, West Lafayette, IN 47907 \\ ${ }^{3}$ Dyson School of Applied Economics and Management, Cornell University, Ithaca, NY 14853
}

\begin{abstract}
Cheese is a widely consumed product in American diets and an important economic driver of US dairy markets. Given the widespread interest in credence attributes of fluid dairy products, the lack of knowledge of demand for animal welfare, environmental, and other credence attributes in cheeses is surprising. Increasing attention surrounding dairy cattle welfare has been placed on the disbudding or dehorning of dairy cattle, in addition to the longer term debates surrounding pasture access and antibiotic use. This work estimates willingness to pay for these attributes of dairy cattle management systems for Cheddar cheese in a nationally representative sample of 749 US household members. Ninety percent of respondents indicated they or someone in their household consumed cheese in the last year. Higher proportions of respondents with children in the household purchased cheese of any kind. Respondents had positive willingness to pay for Cheddar cheese that had the following attributes: USDA-, retailer-, and industry-verified antibiotic use not permitted, required pasture access, and dehorning with pain relief as well as polled (when compared with dehorning without pain relief). As dairy producers face tighter margins and shifting consumer preferences, increasing attention on consumer preferences for cheese may aid in increasing profitability if demanded attributes can be profitability provided.
\end{abstract}

Key words: willingness to pay, Cheddar cheese, dairy product, consumer preference

\section{INTRODUCTION}

Fluid dairy milk has long been a staple of American diets. However, per capita fluid dairy milk consumption has been steadily decreasing since the 1980s

Received May 28, 2019.

Accepted November 30, 2019.

*Corresponding author: birc@purdue.edu
(Dairy Data, 2017), in part due to increases in beverage choices (Durisin, 2017). In comparison, consumption of other products made from milk such as yogurt, butter, and cheese has been steadily increasing (Dairy Data, 2017; Durisin, 2017; Reiter, 2017). Cheese is the single largest use of milk in the United States and the primary driver of farm milk price (Maynard et al., 2005; Wolf and Olynk Widmar, 2014; Dairy Data, 2017). Given these market trends, dairy producers may want to consider shifting their focus from meeting the production methods consumers prefer for fluid milk to production methods consumers prefer (and may be willing to pay a premium for) in cheese production. Although several studies have evaluated preferences of US consumers for dairy products, the authors are not aware of any studies that have explicitly considered these preferences for cheese.

In a nationally representative survey, Widmar et al. (2017) found that $12 \%$ of respondents had altered their dairy consumption due to animal welfare concerns. Additionally, out of the dairy production practices studied, tail docking and dehorning were perceived as the least beneficial and most negative with respect to animal welfare by respondents (Widmar et al., 2017). Common practical reasons for disbudding or dehorning include improved safety of farmers and farm employees, fewer injuries within herd, decreased aggressive behavior, and less carcass damage (AVMA, 2014). Although these procedures produce benefits, they do cause pain. The American Veterinary Medical Association (AVMA) recommends the use of methods that minimize pain. Recommendations include the use of local anesthetics and nonsteroidal anti-inflammatory drugs to alleviate intraoperative and postoperative pain, disbudding rather than dehorning or dehorning at the earliest possible age, and the use of polled genetics (AVMA, 2014, 2018). Despite the pain mitigation recommendations by the AVMA, the only requirement regarding dehorning in the FARM 4.0 program, which goes into effect in 2020 , is that disbudding must occur before 8 wk of age (FARM, 2019). 
Public perceptions and additional labeling requirements have affected the use of pain medication in common agricultural procedures. In Germany, as of 2012, piglet castration without pain medication was no longer allowed under organic production labels (Commission Regulation, 2008). Although immunocastration was an option under the organic label, Heid and Hamm (2012) found that consumers preferred castration with anesthesia and analgesia mainly due to concerns regarding hormone residues. Similar to organic labeling requirements for pork in Germany, future requirements for specialty labeling regarding dehorning may affect dairy industry production practices.

Willingness to pay (WTP) is a commonly used method of evaluating consumer demand and preferences for food products. Evaluating consumer preferences for cheese attributes is timely given its importance in the dairy marketplace and the increasing role of production-related attributes in consumers' conversations. Recent studies regarding consumer demand for cheese have been conducted in Europe, such as the Napolitano et al. (2010) study that evaluated Italian consumers' WTP for organic Pecorino cheese and the Krystallis and Chryssohoidis (2005) study of Greek consumers' WTP for organic feta cheese. American consumers are unlikely to have the same preferences as their European counterparts as differences in food product preferences have been previously documented (Nelson, 2001). By including 3 specific methods (disbudding, disbudding with pain relief, and polled) that result in cattle without horns, this work aims to further expand on the work by Widmar et al. (2017). The objectives of this work are to analyze consumers' purchasing preferences for cheese and determine WTP for Cheddar cheese that is certified as antibiotic use not permitted, pasture access, and more humane dehorning practices using a WTP experimental design, and a national level survey of US consumers.

\section{MATERIALS AND METHODS}

The survey instrument was administered in April 2017 using Qualtrics (https://www.qualtrics.com/), an online survey tool, to accumulate demographic information and dairy product purchasing behavior from US residents. Seven hundred forty-nine random respondents answered specific cheese-purchasing-behavior questions and participated in a WTP choice experiment focusing on WTP for animal-welfare-increasing attributes in Cheddar cheese. The respondents randomly selected to answer these questions were part of a larger data collection that resulted in 2,249 responses. Lightspeed GMI (Bridgewater, NJ) was used to obtain survey respondents through the use of a large opt-in panel database. Respondents were required to be 18 yr of age or older to participate. Using quotas in Qualtrics, the sample was targeted to be representative of the US population in terms of sex, income, education, and geographical region of residence as defined by the US Census Bureau (US Census Bureau, 2016). Regions of residence were defined as in the Census Bureau Regions and Divisions. The overall survey was designed to collect basic demographic information as well as information regarding dairy product purchasing preferences. Frequencies were calculated for categorical variables and means were calculated for the continuous variables. The test of proportions was conducted to determine the statistical representativeness of the survey respondents by comparing percentages of demographic groups from the sample to the targeted population, the US Census.

\section{Cheese Purchasing Behavior}

Respondents were asked about the frequency and specific type of cheese products they purchased. Respondents were asked to select the frequency and reasons they consumed cheese, which included the following: consumed as a snack, used in baked goods, and used in cooking or preparing foods. Respondents were also asked to select the frequency of consumption for a variety of cheese products ranging from cheese sticks to spray or canned cheese. Cheese purchasing and use behaviors were further analyzed using cross tabulations, a form of chi-squared analysis, to determine if usage and consumption varied between different demographics including sex, age, children in the household, and region of residence.

\section{WTP for Production Practices in Cheese}

Cheese may be distinct from other dairy products in the sheer volume of varieties that are available, in addition to the extremely wide price range across those products (Kupiec and Revell, 1998). Other dairy products, including ice cream and yogurt, for example, have varying flavors available and numerous variations in the marketplace. Cheese, however, has numerous distinct varieties and products, many of which are not widely regarded as substitutes for one another, and has become a food of haute cuisine (Fox, 1993). In 2015, Americans consumed on average $16.78 \mathrm{~kg}$ (37 pounds) of cheese per person of which $4.61 \mathrm{~kg}$ (10.16 pounds) was Cheddar cheese and $5.11 \mathrm{~kg}$ (11.27 pounds) was mozzarella cheese (Dairy Data, 2017). The high consumption of mozzarella is due to its use in Italian recipes (pizza) as well as its availability in multiple forms (shredded, whole). Because of the wide variety of uses for mozzarella, Cheddar cheese was selected over moz- 
zarella to be the representative block of cheese for the WTP experiment.

Dehorning or disbudding of cattle is a routine management procedure performed on horned dairy animals. The USDA's National Animal Health Monitoring System Dairy 2014 report found that $94.3 \%$ of surveyed dairy operations disbudded or dehorned their heifer calves. Disbudding involves the destruction of the corium or horn-producing cell of the horn bud before their attachment to the skull. Dehorning involves the more invasive removal of horns after they have attached to the skull, which occurs at approximately 2 mo of age (USDA, 2014). Due to consumer concern as demonstrated by previous studies including Widmar et al. (2017), dehorning and disbudding were included specifically as attributes in this WTP experiment.

Olynk et al. (2010) studied US consumer WTP for individual crates/stalls, pasture access, antibiotic use, and certified trucking/transport for fluid dairy milk as well as pork chops. They found that respondents were willing to pay more for USDA-verified pasture access, individual crates/stalls, and antibiotic use when compared with the other verification entities (Olynk et al., 2010). This is consistent with the findings of Loureiro and Umberger (2007), who found that respondent preferences for ribeye steak attributes, such as traceability and food safety, country-of-origin labeling, and tenderness, were dependent on the certification entity. This preference for certification entities is especially important when considering credence attributes, such as animal welfare production practices, that cannot be discerned by looking at the finished product. Similar results regarding respondent preference in terms of higher WTP for USDA verification were found by Wolf et al. (2011) regarding fluid dairy milk. Olynk and Ortega (2013) found that respondents were willing to pay a positive amount for USDA-verified pasture access and antibiotic use for both yogurt and ice cream. Interestingly, for most attributes considered in their study, respondents had a higher WTP as a fraction of the average product price for yogurt when compared with ice cream (Olynk and Ortega, 2013). This finding demonstrates that WTP for animal welfare attributes can differ between similar products and the need for further research of individual dairy products to better understand consumer preferences. Therefore, attributes included antibiotics permitted (2 levels, yes or no), price (5 levels, ranging from $\$ 1.49$ to $\$ 5.49$ ), certification entity (3 levels, USDA process verification program, dairy industry, or retailer), pasture access (2 levels, yes or no), and dehorning (3 levels, disbudding, disbudding with pain relief, or polled). An example WTP choice scenario is presented in Figure 1. Respondents were shown information explaining each of the attributes in the choice experiment (available in the Appendix) before answering any choice questions. Respondents were asked to choose between two 226.80-g (8-ounce) blocks of Cheddar cheese that were exactly the same in terms of similar color, brand, and flavor, with the exception of the different combinations of attribute levels as detailed above, and the option "I choose not to purchase either item."

The specific combination of attribute levels presented in the choice experiment to respondents, resulting in a main effects plus 2 way interaction experimental design, was determined using the SAS OPTEX program (SAS Institute Inc., 2014; Lusk and Norwood, 2005). The main effects plus 2-way interaction model was chosen because the production attributes were never presented in a choice scenario without a certifying entity. Furthermore, without something specific to certify, the interpretation of the certifying entity would be nonsensical. Reed Johnson et al. (2013) states that including interactions terms requires consideration of theory, intuition, as well as sample size and survey design limitations. When the decision is made to not include interactions, researchers are imposing the assumption that the interactions are not statistically dif-

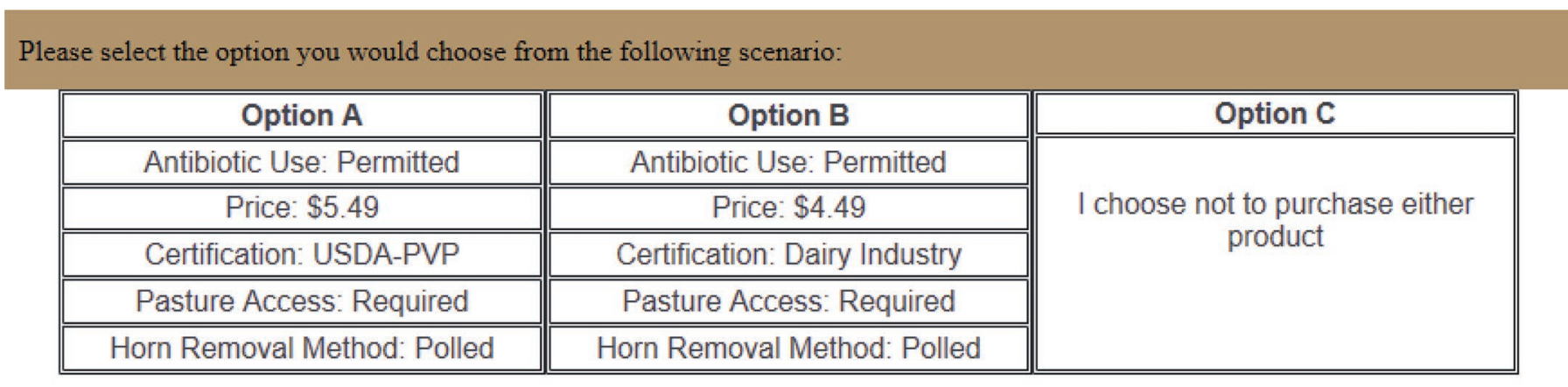

Figure 1. Example willingness to pay choice set. PVP = Process Verified Programs. 
ferent from zero or are independent of the remaining attribute effects if they are significant (Reed Johnson et al., 2013). If these assumptions are not true then the effects will be confounded with the main effects, resulting in biased estimates (Reed Johnson et al., 2013). The same approach of interacting certifying entities and production attributes was employed by Olynk et al. (2010). The design was chosen based on maximizing the D-efficiency. Eighty was the D-efficiency of the chosen experimental design, which contained 37 choice scenarios. The 37 choice scenarios were randomly divided into 4 blocks, 1 containing 10 choice scenarios, and 3 containing 9 choice scenarios. The respondents who were randomly assigned to the WTP experiment within the overall survey were then randomly assigned to 1 of the 4 blocks.

Choice experiments are based on random utility theory. The probability $(P)$ that respondent $n$ chooses alternative $i$ over alternative $j$, which represents maximizing utility $(U)$ with deterministic component $V_{\text {nit }}$, if $U_{n i t}>U_{n j t} \forall j \neq i$ and the error term $\varepsilon$, as outlined by Train (2009), is represented by

$$
P_{n i t}=\operatorname{Prob}\left(V_{n i t}+\varepsilon_{n i t}>V_{n j t}+\varepsilon_{n j t} ; \forall_{j} \in C, \forall_{j} \neq i\right) \cdot[1]
$$

Given the underlying distribution of the error term, equation [1] can be condensed to

$$
P_{n i t}=\frac{\exp \left(V_{n i t}\right)}{\sum_{j} \exp \left(V_{n j t}\right)} .
$$

This analysis would be of interest to dairy producers, processors, and distributors of dairy products. Improved understanding of consumer WTP for Cheddar cheese attributes can help the dairy industry further explore animal welfare credence attributes, as well as the certification entities that are most valuable to consumers.

The random utility of a selection is defined as

$$
\begin{aligned}
& V_{i t}=\beta_{1} \text { Price }_{i t}+\beta_{2} U S D A \_ \text {Antibiotics } i t \\
& +\beta_{3} \text { Retailer_Antibiotics }_{i t}+\beta_{4} \text { Industry_Antibiotics }{ }_{i t} \\
& +\beta_{5} U S D A \_ \text {Pasture }_{i t}+\beta_{6} \text { Retailer_Pasture }_{i t} \\
& +\beta_{7} \text { Industry_Pasture }_{i t}+\beta_{8} U S D A \_ \text {polled }_{i t} \\
& +\beta_{9} \text { Retailer_polled }_{i t}+\beta_{10} \text { Industry_polled }_{i t} \\
& +\beta_{11} U S D A \_ \text {Disbudpainrelief }{ }_{i t} \\
& +\beta_{12} \text { Retailer_Disbudpainrelief }{ }_{i t} \\
& +\beta_{13} \text { Industry_Disbudpainrelief }_{i t}+\beta_{14} \text { Optout }_{i t} \\
& +\beta_{15} \text { Optout_INC } i t+\beta_{16} \text { Optout_Buycheese } i t \text {, }
\end{aligned}
$$

where Price is the price a consumer is willing to pay for a 226.80-g (8-ounce) block of Cheddar cheese; Optout is a constant that represents the respondent's disutility from having to walk away from the purchase of an 226.80-g (8-ounce) block of Cheddar cheese; USDA_Antibiotics, Retailer_Antibiotics, and Industry_Antibiotics are the effects-coded interaction terms between the certification entities and Antibiotics (where Antibiotics indicates the producer was allowed to use antibiotics); USDA_Pasture, Retailer_Pasture, and Industry_Pasture are the effects-coded interaction terms between the certification entities and Pasture (where Pasture indicates the animals had pasture access); and USDA_Disbud, Retailer_Disbud, Industry_Disbud and USDA_Disbudpainrelief, Retailer_Disbudpainrelief, and Industry_Disbudpainrelief are the effects-coded interaction terms between the certification entities and the horn removal method (where Disbud indicates the method of disbudding and Disbudpainrelief indicates the method of disbudding with pain relief). Optout INC and Optout_Buycheese are the interaction between the disutility of having to walk away from a cheese purchase, the income of the respondent, and whether they have purchased cheese for their household in the past. Other demographics such as age were considered within the model, but income and buying cheese were determined the most informative in terms of consistent statistical significance.

The mean WTP for the RPL model is calculated as the negative of the ratio of the coefficient of the verified attribute and the coefficient of price (Adamowicz et al., 1994). For example, the WTP for USDA-verified antibiotic use not permitted cheese can be calculated as

$$
\mathrm{WTP}=-2 \frac{\beta_{2}}{\beta_{1}} .
$$

The 2 in Equation 4 accounts for the effects coding of the various levels of the attributes. For example, attributes with 3 levels such as dehorning method were coded as $-1,0$, and 1 and attributes with 2 levels were coded with -1 and 1 , unlike typical 0, 1 dummy coding (Adamowicz et al., 1994). This prevented confounding with the option opt-out and the left-out dummy variable was not incorporated into the intercept as is true with traditional dummy variable estimation (Adamowicz et al., 1994). Due to the nature of the interactions between opting out of purchasing cheese, age of respondent, and whether the respondent purchases cheese, the WTP (disutility) experienced by walking away from the purchase is calculated differently than the other attributes. For example, the WTP of a respondent who purchases cheese (if the respondent did 
Table 1. Demographic information and comparison to the US Census

\begin{tabular}{|c|c|c|}
\hline Demographic variable & $\begin{array}{l}\% \text { of all respondents } \\
\qquad(\mathrm{n}=749)\end{array}$ & $\begin{array}{l}\text { US Census } \\
(\%)\end{array}$ \\
\hline \multicolumn{3}{|l|}{ Sex } \\
\hline Male & 43 & 49 \\
\hline \multicolumn{3}{|l|}{ Age } \\
\hline Under 18 & - & - \\
\hline $18-24$ & 12 & 13 \\
\hline $25-34$ & 17 & 18 \\
\hline $35-44$ & 14 & 16 \\
\hline $45-54$ & 18 & 17 \\
\hline $55-65$ & 19 & 17 \\
\hline $66-88$ & 20 & 19 \\
\hline Number of adults in my family $(\mathrm{n}=747)$ & 2.06 & - \\
\hline Number of children in my family $(\mathrm{n}=737)$ & 0.67 & - \\
\hline \multicolumn{3}{|l|}{ Annual pretax household income } \\
\hline$\$ 0-24,999$ & 23 & 22 \\
\hline$\$ 25,000-49,999$ & 26 & 23 \\
\hline$\$ 50,000-74,999$ & 18 & 17 \\
\hline$\$ 75,000-99,999$ & 12 & 12 \\
\hline$\$ 100,000$ and higher & $21^{*}$ & $26^{*}$ \\
\hline \multicolumn{3}{|l|}{ Educational background } \\
\hline Less than high school & $4^{*}$ & $13^{*}$ \\
\hline High school graduate (includes equivalency) & 30 & 28 \\
\hline Some college, no degree & $24^{*}$ & $21^{*}$ \\
\hline Associate's degree or bachelor's degree & $30^{*}$ & $27^{*}$ \\
\hline Graduate or professional degree & 12 & 12 \\
\hline \multicolumn{3}{|l|}{ Region of residence } \\
\hline Northeast & 18 & 18 \\
\hline South & $35^{*}$ & $21^{*}$ \\
\hline Midwest & $23^{*}$ & $38^{*}$ \\
\hline West & 24 & 24 \\
\hline
\end{tabular}

*The percentage of respondents and the US Census are different at the $<0.05$ level.

not purchase cheese, $\beta_{16}$ would not be included), and reported an income of $\$ 25,000-49,999$ with a multiplier of 2 (respondents with an income of $\$ 0-24,999$ would have a multiplier of $1, \$ 50,000-74,999$ would have a multiplier of $3, \$ 75,000-99,999$ would have a multiplier of 4 , and incomes of $\$ 100,000$ and higher would have a multiplier of 5) would be calculated as

$$
\mathrm{WTP}=-\frac{\beta_{14}+\beta_{15} \times 2+\beta_{16}}{\beta_{1}} .
$$

To account for the variability in the estimations, the Krinsky and Robb method of parametric bootstrapping was used to calculate $95 \%$ confidence intervals (Krinsky and Robb, 1986; Olynk and Ortega, 2013).

\section{RESULTS}

The sample of respondents closely matched that of the US population with a few exceptions (Table 1). The sample contained a lower percentage of respondents, when compared with the US Census, with an income of $\$ 100,000$ and higher (21 vs. $26 \%$ ), less than a high school degree (4 vs. 13\%), and residence in the Midwest (23 vs. $38 \%$ ). A higher percentage of respondents had some college, no degree earned (24\%), an associate's degree or bachelor's degree earned (30\%), and from the South (35\%), when compared with the US Census: 21, 27 , and $21 \%$, respectively.

\section{Dairy Product Purchasing Behavior}

Respondents were asked a series of questions regarding their cheese purchases to understand dairy product shopping behavior (Table 2). In response to frequency of reading information on meat, egg, or milk product packaging while making a purchasing decision, a higher percentage of respondents selected sometimes (31\%), followed by rarely $(23 \%)$ and usually $(21 \%)$. The lowest percentage of respondents (10\%) selected never. Of those that read information at least rarely, higher percentages of respondents read the information price (83\%), product sell-by date $(72 \%)$, and nutritional information (52\%). Only $12 \%$ of respondents read the information about other production practice information (besides animal welfare).

The majority of respondents $(90 \%)$ indicated they or someone in their household consumed cheese of any type at least 4 times a year. To understand potential decreases in cheese consumption of any type, respon- 
Table 2. Cheese shopping behavior

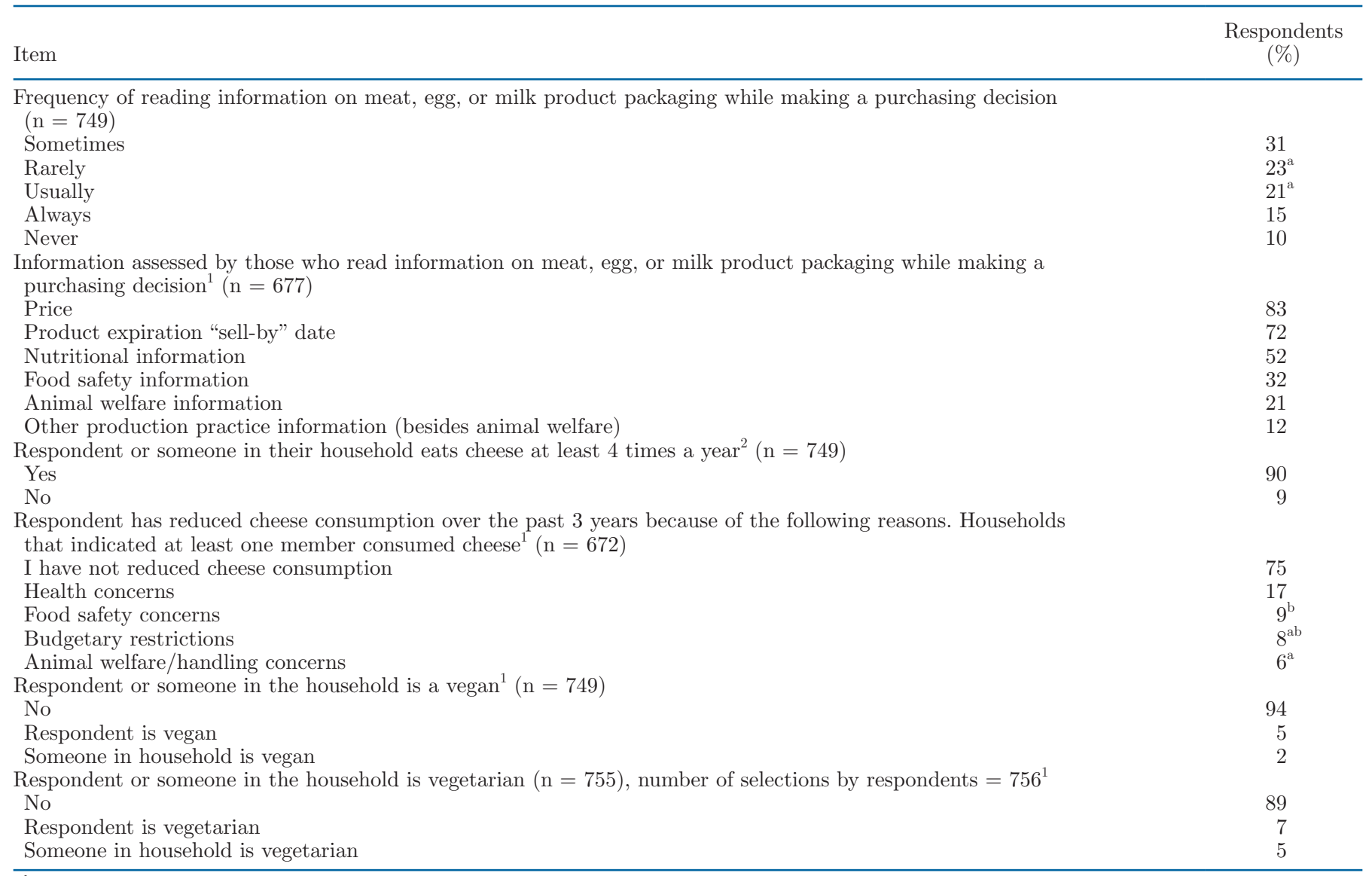

\footnotetext{
${ }_{\mathrm{a}, \mathrm{b}}$ Matching superscript letters indicate that the percentages of respondents for 2 answer choices are not different at the $<0.05$ level. ${ }^{1}$ Multiple selections allowed.

${ }^{2}$ Option choice "I don't know" not included for brevity.
}

dents were asked if they or someone in their household had reduced cheese consumption in the past year, and, if so, the reasons why. The majority of respondents $(75 \%)$ indicated they had not reduced cheese consumption in the past year. Seventeen percent of respondents indicated they had reduced cheese consumption due to health concerns. The majority of respondents were not vegan or vegetarian, and did not have a member of their household who was (94 and 89\%, respectively).

Respondents were asked to indicate what they used cheese for, the types of cheese they consumed, and the frequency of consumption (Table 3). The type of cheese, such as mozzarella, Cheddar, and so on, was not specified in these questions. A higher percentage of respondents used cheese for cooking or preparing foods (97\%), followed by consumed as a snack (95\%). Of those who indicated they purchased cheese as a snack, a higher percentage purchased snack cheese weekly $(45 \%)$, followed by daily $(26 \%)$ and monthly $(17 \%)$. A higher percentage of those who purchased cheese for use in baked goods did so for holidays/special occasions (27\%). For use in cooking or preparing foods, a higher percentage of respondents purchased cheese weekly $(50 \%)$, followed by monthly (21\%) and daily (18\%), which were not different. The highest percentages of respondents purchased cheese slices (92\%), shredded cheese (90\%), grated cheese (87\%), and blocks of cheese (84\%). Cheese wheels and cheese balls were purchased by the lowest percentages of respondents (33 and $41 \%$ respectively). Higher percentages of respondents purchased cheese sticks (33\%), shredded cheese (50\%), blocks of cheese (42\%), and grated cheese (51\%) weekly when compared with other purchasing frequencies. For cubed cheese (28\%), cheese wheels (21\%), cheese balls $(27 \%)$, liquid cheese products (30\%), and spray or canned cheese (15\%), a higher percentage of respondents purchased the products for holidays or special occasions when compared with other purchasing frequencies. Among the cheese products, a higher percentage of respondents $(36 \%)$ purchased cheese slices weekly. 
Table 3. Cheese consumption information of respondents who indicated at least someone in their household purchased cheese $(\mathrm{n}=672)$

\begin{tabular}{|c|c|c|c|c|c|c|}
\hline Item & $\begin{array}{l}\text { Respondent } \\
\text { consumes/buys }\end{array}$ & Daily & Weekly & Monthly & $\begin{array}{l}\text { Holidays/ } \\
\text { special } \\
\text { occasions }\end{array}$ & $\begin{array}{l}\text { I don't know this } \\
\text { product/have } \\
\text { never heard of it }\end{array}$ \\
\hline \multicolumn{7}{|l|}{ Reason for consumption } \\
\hline $\begin{array}{l}\text { Consumed as a snack (for example, cheese } \\
\text { sticks, slices, or cubes) }\end{array}$ & 95 & 26 & $45^{\mathrm{D}}$ & $17^{\mathrm{D}}$ & $6^{\mathrm{a}, \mathrm{D}}$ & $1^{\mathrm{a}, \mathrm{D}}$ \\
\hline Used in baked goods & 77 & $5^{\mathrm{a}, \mathrm{D}}$ & $20^{\mathrm{b}}$ & $20^{\mathrm{b}, \mathrm{D}}$ & 27 & $5^{\mathrm{a}}$ \\
\hline \multicolumn{7}{|l|}{ Type of cheese purchased } \\
\hline Shredded cheese & $90^{\mathrm{AB}}$ & & 29 & $50^{\mathrm{A}}$ & $11^{\mathrm{E}}$ & $1^{\mathrm{D}}$ \\
\hline Grated cheese (for example, Parmesan) & $87^{\mathrm{BC}}$ & & $17^{\mathrm{a}, \mathrm{D}}$ & $51^{\mathrm{A}}$ & $19^{\mathrm{a}, \mathrm{DA}}$ & $1^{\mathrm{D}}$ \\
\hline Blocks of cheese & $84^{\mathrm{C}}$ & & $21^{\mathrm{a}}$ & $42^{\mathrm{E}}$ & $21^{\mathrm{a}, \mathrm{D}}$ & $2^{\mathrm{DB}}$ \\
\hline Cheese sticks & 68 & & $16^{\mathrm{a}, \mathrm{D}}$ & 33 & $19^{\mathrm{a}, \mathrm{DA}}$ & $1^{\mathrm{D}}$ \\
\hline Cubed cheese & $52^{\mathrm{D}}$ & & $8^{\mathrm{A}}$ & $16^{\mathrm{D}}$ & $28^{\mathrm{B}}$ & $3^{\mathrm{ABE}}$ \\
\hline Liquid cheese products or cheese dips & $51^{\mathrm{D}}$ & & $7^{\mathrm{A}}$ & $14^{\mathrm{D}}$ & $30^{\mathrm{B}}$ & $4^{\mathrm{EC}}$ \\
\hline
\end{tabular}

${ }^{\mathrm{a}, \mathrm{b}}$ Matching lowercase letters indicate that percentages are not different at the $<0.05$ level across a row of the table. For example, the percentage of respondents who selected they consumed cheese as a snack is not different than the percentage who selected "I don't know."

${ }^{A-E}$ Matching uppercase letters indicate that percentages are not different at the $<0.05$ level within a column of the table for each section (either reason for consumption or type of cheese purchased). For example, the percentage of respondents who selected they use cheese as a snack weekly is not different than the percentage of respondents who use cheese weekly in cooking or preparing foods.

Cheese consumption and purchasing behavior differed between demographics including sex, age, children in the household, and region of residence (Appendix Tables A1 and A2). Higher percentages of women consumed cheese for holidays/special occasions $(35.2 \%)$ and lower percentages consumed cheese daily (29.8\%) when compared with the percentage of men (28.1 and $37.5 \%$, respectively). Higher percentages of women $(47.8 \%)$ purchased cheese sticks when compared with men (39.7\%). Conversely, higher percentages of men purchased cheese wheels $(15.3 \%)$ and spray or canned cheese $(56.0 \%)$ when compared with women (8.6 and $43.4 \%$ respectively). Although statistical differences were observed between the age groups regarding purchasing behavior for frequency of consumption and type of cheese purchased, most behaviors did not have clear age-related trends. Higher percentages of respondents under $55 \mathrm{yr}$ of age purchased cheese sticks when compared with those 55 and older, whereas a lower percentage of respondents 55 and older purchased cheese wheels.

Respondents with children in their household had higher proportions who had purchased cheese in general, purchased cheese daily, and purchased all types of cheese included in this study. Higher percentages of respondents in the South (46.0\%) purchased cubed cheese when compared with the Midwest (46.7\%) and West $(45.2 \%)$. Additionally, higher percentages of respondents in the South purchased shredded cheese $(76.2 \%)$ when compared with the Northeast $(66.7 \%)$ and West
(61.0\%). A lower percentage of respondents from the West (62.2\%) purchased sliced cheese when compared with all other regions.

\section{WTP for Production Practices in Cheese}

All of the coefficients in the random parameters logit model of WTP for Cheddar cheese were significant at the 0.10 level or lower (Table 4). The standard deviations for many of the coefficients were significant, indicating heterogeneity among the respondents. The variable opt-out indicates how much disutility in the form of dollars lost the respondent experiences when walking away from a Cheddar cheese purchasing opportunity due to their preferences not being met. This variable was crossed with respondent demographics including income and whether or not the respondent indicated they purchased cheese. As the income of cheese-buying respondents increased from $\$ 0-24,999$ to $\$ 100,000+$, the disutility they experienced from not making the Cheddar cheese purchase on average increased from -\$8.54 to -10.32 per 226.80 -g (8-ounce) block. This finding was significantly different based on overlapping confidence intervals. The disutility experienced in terms of negative dollars experienced by those who indicated they did not purchase Cheddar cheese was not as great, but still increased as income increased. Non-cheese-buyers with an income of \$0-24,999 had an opt-out WTP of $-\$ 4.97$ per 226.0-g (8-ounce) block of Cheddar cheese and non-cheese-buyers with an in- 
Table 4. Random parameters logit model results: willingness to pay (WTP) for attributes of Cheddar cheese $(\mathrm{n}=749)$

\begin{tabular}{|c|c|c|c|}
\hline Attributes & $\begin{array}{l}\text { Coefficient } \\
\quad(\mathrm{SE})\end{array}$ & $\begin{array}{l}\text { SD } \\
\text { (SE) }\end{array}$ & $\begin{array}{l}\text { WTP, } \$ \\
(95 \% \text { CI })\end{array}$ \\
\hline USDA-verified antibiotic use not permitted & $\begin{array}{l}0.7186^{* * *} \\
(0.0677)\end{array}$ & $\begin{array}{l}0.9087^{* * *} \\
(0.0858)\end{array}$ & $\begin{array}{l}2.35 \\
(1.88,2.79)\end{array}$ \\
\hline USDA-verified pasture access required & $\begin{array}{l}0.8500^{* * *} \\
(0.0712)\end{array}$ & $\begin{array}{r}0.1652 \dagger \\
(0.0972)\end{array}$ & $\begin{array}{l}2.78 \\
(2.31,3.31)\end{array}$ \\
\hline USDA-verified polled & $\begin{array}{l}0.4792^{* * *} \\
(0.0726)\end{array}$ & $\begin{array}{r}0.2249 \dagger \\
(0.0862)\end{array}$ & $\begin{array}{l}1.57 \\
(1.11,2.08)\end{array}$ \\
\hline USDA-verified dehorned with pain relief & $\begin{array}{l}0.4659^{* * *} \\
(0.0812)\end{array}$ & $\begin{array}{l}0.6496^{* * *} \\
(0.0856)\end{array}$ & $\begin{array}{l}1.53 \\
(1.02,2.06)\end{array}$ \\
\hline Retailer-verified antibiotic use not permitted & $\begin{array}{l}0.4576^{* * *} \\
(0.0836)\end{array}$ & $\begin{array}{c}0.3303 \\
(0.1420)\end{array}$ & $\begin{array}{l}1.50 \\
(0.96,2.00)\end{array}$ \\
\hline Retailer-verified pasture access required & $\begin{array}{l}0.8607^{* * *} \\
(0.0918)\end{array}$ & $\begin{array}{l}0.5971^{* * *} \\
(0.1152)\end{array}$ & $\begin{array}{l}2.82 \\
(2.26,3.42)\end{array}$ \\
\hline Retailer-verified polled & $\begin{array}{l}0.4221^{* * *} \\
(0.0925)\end{array}$ & $\begin{array}{l}0.2214^{* * *} \\
(0.1509)\end{array}$ & $\begin{array}{l}1.38 \\
(0.75,1.96)\end{array}$ \\
\hline Retailer-verified dehorned with pain relief & $\begin{array}{r}0.2889 \dagger \\
(0.0975)\end{array}$ & $\begin{array}{c}0.3762^{*} \\
(0.1208)\end{array}$ & $\begin{array}{l}0.95 \\
(0.34,1.57)\end{array}$ \\
\hline Industry-verified antibiotic use not permitted & $\begin{array}{l}0.7628^{* * *} \\
(0.0748)\end{array}$ & $\begin{array}{c}0.0119 \\
(0.1070)\end{array}$ & $\begin{array}{l}2.50 \\
(2.00,2.96)\end{array}$ \\
\hline Industry-verified pasture access required & $\begin{array}{l}0.5982^{* * *} \\
(0.0767)\end{array}$ & $\begin{array}{c}0.0270 \\
(0.1166)\end{array}$ & $\begin{array}{l}1.96 \\
(1.46,2.47)\end{array}$ \\
\hline Industry-verified polled & $\begin{array}{l}0.3718^{* * *} \\
(0.0863)\end{array}$ & $\begin{array}{c}0.1868 \\
(0.1204)\end{array}$ & $\begin{array}{l}1.22 \\
(0.64,1.84)\end{array}$ \\
\hline Industry-verified dehorned with pain relief & $\begin{array}{l}0.2626^{* * *} \\
(0.0766)\end{array}$ & $\begin{array}{c}0.2340 \\
(0.1235)\end{array}$ & $\begin{array}{l}0.86 \\
(0.33,1.38)\end{array}$ \\
\hline Opt out & $\begin{array}{l}-2.6703^{* * *} \\
(0.4944)\end{array}$ & $\begin{array}{c}0.2627 \\
(0.3718)\end{array}$ & \\
\hline Price & $\begin{array}{l}-0.6105^{* * *} \\
(0.0300)\end{array}$ & & \\
\hline Opt out income $\$ 0-24,999$ cheese buyer & $-5.2151^{* * *}$ & & $\begin{array}{l}-8.54 \\
(-9.46,-7.65)\end{array}$ \\
\hline Opt out income $\$ 25,000-49,999$ cheese buyer & $-5.5767^{* * *}$ & & $\begin{array}{l}-9.13 \\
(-10.01,-8.28)\end{array}$ \\
\hline Opt out income $\$ 50,000-74,999$ cheese buyer & $-5.9382^{* * *}$ & & $\begin{array}{l}-9.73 \\
(-10.69,-8.87)\end{array}$ \\
\hline Opt out income $\$ 75,000-99,999$ cheese buyer & $-6.2998^{* * *}$ & & $\begin{array}{l}-10.32 \\
(-11.31,-9.39)\end{array}$ \\
\hline Opt out income $\$ 100,000+$ cheese buyer & $-6.6613^{* * *}$ & & $(-10.91$ \\
\hline Opt out income $\$ 0-24,999$ & $-3.0318^{* * *}$ & & $\begin{array}{l}-4.97 \\
(-6.36,-3.45)\end{array}$ \\
\hline Opt out income $\$ 25,000-49,999$ & $-3.3934^{* * *}$ & & $\begin{array}{l}-5.56 \\
(-6.98,-4.10)\end{array}$ \\
\hline Opt out income $\$ 50,000-74,999$ & $-3.7549^{* * *}$ & & $\begin{array}{l}-6.15 \\
(-7.57,-4.74)\end{array}$ \\
\hline Opt out income $\$ 75,000-99,999$ & $-4.1165^{* * *}$ & & $\begin{array}{l}-6.74 \\
(-8.22,-5.27)\end{array}$ \\
\hline Opt out income $\$ 100,000+$ & $-4.4780^{* * *}$ & & $\begin{array}{l}-7.33 \\
(-8.91,-5.80)\end{array}$ \\
\hline
\end{tabular}

come of $\$ 100,000+$ had an opt-out WTP of $-\$ 7.33$ per 226.80-g (8-ounce) block of Cheddar cheese. The confidence intervals for each income bracket did not overlap between the cheese and non-cheese-buyers, indicating that they were different.

Respondents were willing to pay a positive amount for antibiotic-use-not-permitted Cheddar cheese, which ranged from $\$ 1.50$ to $\$ 2.50$ per 226.80 -g (8-ounce) block of Cheddar cheese depending on the verifier, when compared with cheese without such claims. Based on over- lapping confidence intervals, the WTP for antibioticuse-not-permitted Cheddar cheese did not differ across verifiers. The WTP for verified pasture-access-required Cheddar cheese was positive and ranged from $\$ 1.96$ to $\$ 2.78$ per 226.80 -g (8-ounce) block of cheese depending on the verifier, when compared with Cheddar cheese without pasture-access claims. Again using the overlapping confidence interval method, the WTP did not differ between the verifiers. For all verifiers, respondents were willing to pay a positive amount for Ched- 
dar cheese labeled as verified polled and dehorned with pain relief when compared with the production practice dehorned without pain relief. The WTP did not differ between verified polled and verified dehorned with pain relief for any of the verifiers. For USDA-verified pasture access required, respondents were willing to pay a higher amount when compared with USDA-verified polled and USDA-verified dehorned with pain relief. Respondents were willing to pay a higher amount for retailer-verified pasture access required when compared with all other retailer-verified attributes. For industryverified antibiotic-use-not-permitted Cheddar cheese, respondents were willing to pay a higher amount when compared with industry-verified polled and industryverified dehorned with pain relief.

\section{DISCUSSION}

Reading information on packaging is the primary method for consumers to identify credence attributes, because without labeled information they are unlikely to be discernable (Caswell and Mojduszka, 1996). Therefore, it is not surprising that in this study, $90 \%$ of respondents read label packaging on meat, egg, or milk products at least some of the time. Despite the need for labels to convey credence attributes, the success of labels may be limited due to gaps in understanding of what labels mean, and general consumer confusion (Grunert et al., 2014). Specifically, Anstine (2007) found respondent confusion between the labels natural and organic in dairy milk and yogurt. Only $21 \%$ of respondents read animal welfare information, which was interesting considering the positive WTP for animalwelfare-improving attributes in the WTP for Cheddar cheese experiment. It is possible that respondents did not consider looking for pictorial certification claims or entities as reading or were not considering display signage when answering this question. Furthermore, attributes that may be considered animal welfare improving by some, such as pasture access, may not be labeled as such by other consumers. Pasture access allows for more natural behavior (Hemsworth et al., 1995), and can help improve lameness problems (Hernandez-Mendo et al., 2007) and reduce mastitis (Washburn et al., 2002). However, studies have shown that cows prefer to be in the barn when given free choice during certain weather conditions such as high heat, especially during the day (Legrand et al., 2009; Schütz et al., 2009). Considering the variability of cows' preferences, respondents' ideas of animal welfare improving may differ based on the scenario they are imagining when making their choice. Therefore, there may be mixed interpretation of the appearance of animal welfare labeling on packaging.
The negative effects or benefits of cheese on health may depend on the health status of the individual person. Recent studies have shown that in addition to nutritional benefits, foods such as cheese and yogurt have neutral or beneficial effects on lipid profiles and cardiovascular disease (Siri-Tarino and Krauss, 2016; Chen et al., 2017). However, cheese is high in salt and SFA, which current dietary guidelines recommend reducing (Siri-Tarino and Krauss, 2016). Cheese may also increase cholesterol, increasing risk factors for atherosclerosis (O'Brien and O'Connor, 2017). This may be in part the motivation behind the $17 \%$ of respondents who indicated they decreased cheese intake due to dietary concerns. The highest use for cheese in our survey was for cooking or preparing foods $(97 \%)$. This is likely driven by the high consumption of pizza in the United States because not many substitutes are available for cheese on pizza (Tam, 2017). Higher percentages of respondents purchased cheese in more convenient forms such as shredded, grated, or sliced. Scholliers (2015) conjectured that although convenience foods in a sense have been around since the Middle Ages, their qualities in terms of time saving and handiness are still important to consumers.

The frequency and types of cheese consumed by men and women differed. Higher percentages of women consumed cheese sticks, whereas higher percentages of men consumed cheese wheels or spray-canned cheese. Popular dietary websites describe cheese sticks as a convenient and healthy snack choice, especially for women who may have concerns regarding calcium intake to prevent osteoporosis (Morgan, 2017). Higher percentages of respondents with children in the household purchased every type of cheese when compared with respondents without children. Greer and Krebs (2006) impart the importance of consuming enough calcium during childhood and adolescence to achieve peak bone mass, and recommend cheese and yogurt as an alternative to fluid dairy milk in meeting calcium needs. Vitamins and minerals including calcium, vitamin $\mathrm{A}$, riboflavin, and vitamin $\mathrm{B}_{12}$ are all found in dairy products and are critical in bioavailable matrices that help promote linear growth in children (Nicklas et al., 2013). Parents may be meeting the nutritional needs of their children by providing cheese in different forms as a regular part of their diet. Using Nielsen scanner data, Davis et al. (2011) found that being in the Southern region had a positive effect on demand for cheese, although the particular type of cheese was not differentiated. In this study, higher percentages of Southern residents purchased Cheddar cheese when compared with the Midwest and West. Differences in cheese type purchases between the regions of residence 
may be related to popular regional dishes or various trends in food popularity.

The inclusion of the cheap-talk script is meant to remind respondents of hypothetical bias, and in response reduce the level of bias (Lusk, 2003; Olynk and Ortega 2013). Although the cheap-talk script is unlikely to negatively affect results, Ladenburg et al. (2011) found that using the cheap-talk script did not change demand for reducing visual dis-amenities from offshore wind farms. Hensher (2010) stated that the effects of the cheap-talk script were context specific, and that one could not assume that it works in all contexts. The focus of this experiment was on the likely unknown dairy production practices of dehorning, disbudding and polled. The amount of text presented to respondents before participating in the WTP choice experiment was minimized in an effort to increase focus on the attribute definitions; therefore, the cheap-talk script was not included. Additionally, people may be inclined to answer potentially socially sensitive questions in a way that deviates from the person's true behavior, in an effort to make themselves look better, which is referred to as social desirability bias (SDB; Fisher, 1993). Olynk et al. (2010) found evidence of SDB in respondents' WTP for the milk attribute pasture access. However, evidence of SDB was not found for the attribute antibiotic use (Olynk et al., 2010). It is important to note when considering the results of this study, potential occurrences of SDB and hypothetical bias may result in WTP estimates that are higher than reality. However, due to regional differences in dairy prices that are likely to affect cardinal willingness to pay, the more important interpretation of the results may be in the relative importance of the attributes.

The results regarding the importance (in terms of significantly different WTP) did not differ in this study for any of the attributes of Cheddar cheese studied. This differs from the findings by Olynk et al. (2010), who found significant positive WTP for antibiotic-free milk if it was verified by a consumer group or the USDA, and a negative WTP if it was verified by a private-party group. Similar results were found regarding pork. Respondents were willing to pay significant positive amounts for USDA-verified antibiotic use, but negative amounts for private-party-verified antibiotic use (Olynk et al., 2010). Regarding pasture access, Olynk et al. (2010) found that respondents were willing to pay a positive amount for self-verified, consumer group-verified, and USDA-verified pasture access in milk and pork. In line with the findings of this study, Olynk and Ortega (2013) found that respondents were willing to pay a positive amount for USDA-, industry-, and retail-verified antibiotic free and pasture access for ice cream and yogurt. Perhaps the effects of the verifying agency vary less for Cheddar cheese than they do for other products, or perhaps verification overall is different for cheese than fluid milk or meat products. The reasons why cheese behaves differently than other products with respect to verification are beyond the scope of this analysis, although the lack of significant variation is itself worth noting.

Respondents had a high WTP for antibiotic-use-notpermitted Cheddar cheese for all verifiers. The debate surrounding the use of antibiotics in food animal species is often led by the idea that such widespread use contributes to antimicrobial resistance, which has occurred in enteric bacteria in cattle (Alcaine et al., 2005; Sato et al., 2005). However, those concerned with animal welfare may prefer the judicious, therapeutic use of antibiotics to only treat injured or ill animals as opposed to blanket banning (Oliver et al., 2011). In 2015, more than 90\% of operations administered drugs, not only limited to antibiotics, which required a withdrawal period (USDA, 2014). Despite these high numbers, $\beta$-lactam residues were only found in $0.012 \%$ of tanker loads tested (USDA, 2014). A positive test results in the disposal of the tanker load and possible suspension of the producer's milk selling permit (USDA, 2014). The definition provided regarding no antibiotic use permitted given to respondents in this experiment was stringent: "Not permitted means the animal was raised on an operation claiming to never (under any circumstances), administer antibiotics to animals." It is somewhat surprising that despite the positive WTP for animal-welfare-improving attributes such as pain management, the mean WTP for antibiotic use not permitted was positive. Further research could shed light on what consumers believe happens to animals that become ill or require antibiotics under strict antibioticuse-not-permitted management practices.

Respondents were willing to pay a positive amount for pasture access verified by all certifiers. For USDA and retailer certification, respondents were willing to pay a higher amount for pasture-access-verified Cheddar cheese when compared with dehorning practices. Interestingly, as outlined in the 2014 USDA report, $12.6 \%$ of operations housed pregnant heifers on pasture (USDA, 2014). For lactating cows, $59.6 \%$ of operations allowed pasture access, and $72.3 \%$ of operations allowed pasture access for dry cows (USDA, 2014). As herd size increased, access to pasture access decreased, which resulted in only $19.9 \%$ of lactating cows having pasture access and $34.0 \%$ of dry cows having pasture access (USDA, 2014). It is unlikely that consumers understand that pasture access differs drastically between operations as well as the production stage of the dairy cow. It is interesting to note that despite consumer WTP for pasture access, access to pasture is low at the 
cow level, and not a common practice for all stages of cow production at the operation level.

While the AVMA welfare recommendations help guide US dairy professionals to minimize stress and pain, some countries have established legal guidelines. For example, under the Prevention of Cruelty to Animals Act, Australia prohibits the dehorning of cattle older than 12 mo of age without the use of local anesthetics (NSW, 2018). Under the European Council Directive 98/58/EC (1998), which governs the European Union, animals should not experience unnecessary pain, suffering, or injury (Directive 98/58/EC, 1998). However, governance by the EU directive does not guarantee compliance. The Recommendation Concerning Cattle dictates that with the exception of chemical and heat disbudding in calves less than 4 wk old, disbudding/ dehorning should be carried out under the supervision of a veterinarian (Council of Europe Standing Committee, 1988). Despite these recommendations, individual nations within the European Union can have their own national rules, and a survey conducted by Cozzi et al. (2015) found that EU member farmers frequently performed disbudding/dehorning themselves, including the use of the hot-iron and caustic paste methods, and that pain relief was rarely administered.

As demonstrated by the marketing of products with labels that promote potentially animal welfare improving practices such as pasture access, diet requirement, and dehorning methods (ASPCA, 2018); marketing agencies believe that at least some consumers have concerns regarding the production methods used in dairy operations. Using a nationally representative survey of the United States, Widmar et al. (2017) found that $30 \%$ of respondents felt that tail docking and dehorning contributed negatively to the welfare of dairy cattle. The definition of the 5 freedoms, which is often used as a starting point in animal welfare discussions, includes freedom from pain, injury, or disease (Farm Animal Welfare Council, 1992). Rising concern for animal welfare, as well as legislative changes, indicates that at least some people are concerned with minimizing pain. In this study, respondents were willing to pay a positive amount for both verified polled and dehorned with pain relief for every verifier, and the WTP were not different based on overlapping confidence intervals. This positive WTP for either method may indicate that respondents had a high preference for any dehorning method other than dehorning without pain relief. The preference of respondents for pain relief in castration found by Wolf et al. (2016) may contribute to the idea that people have a preference for pain relief when any medical procedures are being performed on livestock. In a study of Australian consumers, Phillips et al. (2009) found that the use of pain relief was more important than the particular method of dehorning in dairy cattle. In a survey of Canada citizens, Spooner et al. (2014) found that respondents frequently voiced concern about minimizing pain in farm animal production. Given the preference for pain relief, it was somewhat surprising that respondents did not favor the alternative polled over dehorning with pain relief, as it would not require any invasive method of dehorning. Despite being provided with a definition, it is possible that respondents did not make the connection between an animal being polled and not requiring dehorning, therefore, not requiring pain medication. Nonetheless, a recent economic assessment suggests that incorporating polled genetics into a breeding program could still be profitable under current market conditions depending on the availability, cost, and genetic merit of polled genetics (Thompson et al., 2017).

Predictably, respondents who had indicated they purchased cheese felt more disutility in terms of negative WTP when their preferences were not available and they chose opt-out when compared with those who did not indicate they had purchased cheese. The negative WTP for even non-cheese-buyers may indicate that if their preferences were available, they may choose to purchase cheese in the future. As income increased for both cheese buyers and non-cheese-buyers, the disutility of not purchasing cheese increased. As income increases, the percentage of income spent on food decreases (Ziliak, 2001). However, the percentage of the food budget spent on animal protein, which includes cheese, increases with income (Perisse et al., 1969). The increase in disutility from not purchasing cheese at higher income levels may demonstrate that at those income levels the demand for cheese is not satiated. Age crossed with the opt-out option was not significant in this model of WTP for Cheddar cheese. In comparison, Morgan et al. (2016) found that higher percentages of respondents under the age of 44 agreed with the statement "I actively look to purchase milk products which promote welfare-friendly conditions for the livestock animals used to produce them." McKendree et al. (2014) also found that younger respondents were more likely to select concerned regarding the welfare of domestic food animals. However, Widmar et al. (2017) did not find consistent differences in perceptions between the age groups when asking about specific dairy production practices such as the use of hormones, or pasture access. Furthermore, looking at labels or having concern does not necessarily translate into being willing to pay more for specific attributes. More research into the differences between beliefs and preferences between general statements and particular production practices 
are needed to make a conclusion regarding age-related preferences, and perhaps this finding demonstrates the complexity of animal welfare attributes.

Like all research, this particular study has limitations. The attributes included in this work are important to the dairy industry and are often discussed by proponents of animal welfare. Although the nuances of procedures such as dehorning, disbudding, and polled may be familiar within these groups, knowledge regarding these practices are likely unknown by the general public. To help mitigate this issue, respondents were provided with definitions of all attributes included in the WTP experiment. Despite the availability of definitions, there is no guarantee that respondents had a good understanding of the dehorning procedures included. However, this scenario mimics the reality of shopping experiences. In the store, shoppers may be confronted with labels making claims they are not familiar with, and still have to make purchasing decisions with the given information. When developing a survey instrument, a balance must be struck between including enough questions to meet the objectives of the research while minimizing fatigue, which has been shown to decrease data quality (Galesic and Bosnjak, 2009). Future research could include further questions that measure consumer knowledge of dairy production practices, including their prevalence. Determining SDB requires respondents to participate in the WTP experiment twice, as both indirect and direct questions, which was not included in this research. Future research could build on both this work and that of Olynk et al. (2010) by evaluating the prevalence of SDB when conducting choice experiments on dairy production attributes that include pain management such as dehorning.

\section{CONCLUSIONS}

As dairy producers face tighter margins and shifting consumer preferences, increasing attention on consumer preferences for cheese may aid in increasing profitability if demanded attributes can be profitably provided. The majority of respondents indicated they purchased cheese and had not recently decreased their consumption for any reason. Common uses of cheese included cooking or preparing foods, and as a snack. Increasing the availability of different types of cheese in convenience forms may increase sales because forms such as shredded cheese, grated cheese, and blocks of cheese were popular and convenience continues to be a trend driven by busy consumers. Respondents had a positive WTP for Cheddar cheese with verified antibiotic use not permitted and potential animal-welfare-improving production practices: required pasture access, and dehorning with pain relief as well as polled (when compared with dehorning without pain relief). Further research focused on the implementation of practices on farms can help determine if producers can profitably implement these production practices that some people are willing to pay for. In particular, given the focus on pain-inducing procedures in livestock animals in media and consumer groups, additional work on the economics of implementing changes to dehorning practices, including incorporating polled cattle, is warranted.

\section{ACKNOWLEDGMENTS}

This work was funded, in part, by a Faculty Seed Grant provided by the Center for Animal Welfare Science at Purdue University in 2016. The funded project was entitled "Understanding Consumer Perceptions of Dairy Cattle Welfare." Additional information can be found at https://vet.purdue.edu/CAWS/research .php. The funders had no role in study design, data collection and analysis, decision to publish, or preparation of the manuscript. The authors have not stated any conflicts of interest.

\section{REFERENCES}

Adamowicz, W., J. Louviere, and M. Williams. 1994. Combining revealed and stated preference methods for valuing environmental amenities. J. Environ. Econ. Manage. 26:271-292. https://doi.org/ 10.1006/jeem.1994.1017.

Alcaine, S. D., S. S. Sukhnanand, L. D. Warnick, W. L. Su, P. McGann, P. McDonough, and M. Wiedmann. 2005. Ceftiofur-resistant Salmonella strains isolated from dairy farms represent multiple widely distributed subtypes that evolved by independent horizontal gene transfer. Antimicrob. Agents Chemother. 49:4061-4067. https:// doi.org/10.1128/AAC.49.10.4061-4067.2005.

Anstine, J. 2007. Organic and all natural: Do consumers know the difference? J. Appl. Econ. Policy 26.

ASPCA. 2018. Understanding Dairy Labels. ASPCA Meat, Eggs and Dairy Label Guide. Accessed Oct. 29, 2018. https://www.aspca .org/shopwithyourheart/consumer-resources/meat-eggs-and-dairy -label-guide/understanding-dairy-labels.

AVMA. 2014. Welfare Implications of Dehorning and Disbudding Cattle. Accessed Dec. 10, 2018. https://www.avma.org/KB/ Resources/LiteratureReviews/Pages/Welfare-Implications-of -Dehorning-and-Disbudding-Cattle.aspx.

AVMA. 2018. Castration and Dehorning of Cattle. Accessed Dec. 10, 2018. https://www.avma.org/KB/Policies/Pages/Castration-and -Dehorning-of-Cattle.aspx.

Caswell, J. A., and E. M. Mojduszka. 1996. Using informational labeling to influence the market for quality in food products. Am. J. Agric. Econ. 78:1248-1253. https://doi.org/10.2307/1243501.

Chen, G. C., Y. Wang, X. Tong, I. M. Szeto, G. Smit, Z. Li, and L. Qin. 2017. Cheese consumption and risk of cardiovascular disease: A meta-analysis of prospective studies. Eur. J. Nutr. 56:2565-2575. https://doi.org/10.1007/s00394-016-1292-z.

Commission Regulation. 2008. Commission Regulation (EC) No $889 / 2008$ of 5 September 2008 laying down detailed rules for the implementation of Council Regulation (EC) No 834/2007 on organic production and labelling of organic products with regard to organic production, labelling and control.

Council of Europe Standing Committee. 1988. Recommendation concerning cattle adopted by the Standing Committee on 21 October 1988. Accessed Aug. 13, 2019. http://www.coe.int/t/e/ 
legal_affairs/legal_co-operation/biological_safety_and_use_of _animals/farming/Rec\%20cattle\%20E.asp\#TopOfPage.

Cozzi, G., F. Gottardo, M. Brscic, B. Contiero, N. Irrgang, U. Knierim, O. Pentelescu, J. J. Windig, L. Mirabito, F. K. Eveillard, and A. C. Dockès. 2015. Dehorning of cattle in the EU Member States: A quantitative survey of the current practices. Livest. Sci. 179:411. https://doi.org/10.1016/j.livsci.2015.05.011.

Dairy Data. 2017. USDA ERS - Dairy Data. Accessed Dec. 12, 2018. https://www.ers.usda.gov/data-products/dairy-data/.

Davis, C. G., D. Blayney, D. Dong, S. T. Yen, and R. J. Johnson. 2011. Will changing demographics affect US cheese demand? J. Agric. Appl. Econ. 43:259-273. https://doi.org/10.1017/S107407080000420X https://doi.ord/10.1017/S107407080000420X.

Directive 98/58/EC. 1998. Council Directive 98/58/EC of 20 July 1998 concerning the protection of animals kept for farming purposes. OJ L 221, 8.8.1998, p 23.

Durisin, M. 2017. Cheese consumption rescues dairy prices as Americans drink less milk. The Seattle Times. Accessed Oct. 30, 2018. https://www.seattletimes.com/business/cheese-consumption -rescues-dairy-prices-as-americans-drink-less-milk/.

FARM. 2019. FARM Animal Care Version 4.0 Recommended Standards Open Commenting Period. Accessed Aug. 12, 2019. https:// nationaldairyfarm.com/animal-care-open-comments/.

Farm Animal Welfare Council. 1992. The five freedoms. Farm Animal Welfare Council, London, UK.

Fisher, R. J. 1993. Social desirability bias and the validity of indirect questioning. J. Consum. Res. 20:303-315. https://doi.org/10 $.1086 / 209351$.

Fox, P. F. 1993. Cheese: An overview. Pages 1-36 in Cheese: Chemistry, Physics and Microbiology. Springer, Boston, MA.

Galesic, M., and M. Bosnjak. 2009. Effects of questionnaire length on participation and indicators of response quality in a web survey. Public Opin. Q. 73:349-360. https://doi.org/10.1093/poq/nfp031.

Greer, F. R., and N. F. Krebs. 2006. Optimizing bone health and calcium intakes of infants, children, and adolescents. Pediatrics 117:578-585. https://doi.org/10.1542/peds.2005-2822.

Grunert, K. G., S. Hieke, and J. Wills. 2014. Sustainability labels on food products: Consumer motivation, understanding and use. Food Policy 44:177-189. https://doi.org/10.1016/j.foodpol.2013 .12 .001

Heid, A., and U. Hamm. 2012. Consumer attitudes towards alternatives to piglet castration without pain relief in organic farming: Qualitative results from Germany. J. Agric. Environ. Ethics 25:687-706. https://doi.org/10.1007/s10806-011-9350-2.

Hemsworth, P. H., J. L. Barnett, L. Beveridge, and L. R. Matthews. 1995. The welfare of extensively managed dairy cattle: A review. Appl. Anim. Behav. Sci. 42:161-182. https://doi.org/10.1016/0168 -1591(94)00538-P.

Hensher, D. A. 2010. Hypothetical bias, choice experiments and willingness to pay. Transp. Res. B. Methodological 44:735-752. https: //doi.org/10.1016/j.trb.2009.12.012.

Hernandez-Mendo, O., M. A. G. von Keyserlingk, D. M. Veira, and D. M. Weary. 2007. Effects of pasture on lameness in dairy cows. J. Dairy Sci. 90:1209-1214. https://doi.org/10.3168/jds.S0022 -0302(07)71608-9.

Krinsky, I., and A. L. Robb. 1986. On approximating the statistical properties of elasticities. Rev. Econ. Stat. 68:715-719. https://doi .org/10.2307/1924536.

Krystallis, A., and G. Chryssohoidis. 2005. Consumers' willingness to pay for organic food: Factors that affect it and variation per organic product type. Br. Food J. 107:320-343. https://doi.org/10 $.1108 / 00070700510596901$.

Kupiec, B., and B. Revell. 1998. Speciality and artisanal cheeses today: The product and the consumer. Br. Food J. 100:236-243. https://doi.org/10.1108/00070709810221454.

Ladenburg, J., O. Bonnichsen, and J. O. Dahlgaard. 2011. Testing the effect of a short cheap talk script in choice experiments. Danish J. Econ 149:25-54. (Nationaløkonomisk Tidsskrift).

Legrand, A. L., M. A. G. von Keyserlingk, and D. M. Weary. 2009. Preference and usage of pasture versus free-stall housing by lactat- ing dairy cattle. J. Dairy Sci. 92:3651-3658. https://doi.org/10 $.3168 /$ jds.2008-1733.

Loureiro, M. L., and W. J. Umberger. 2007. A choice experiment model for beef: What US consumer responses tell us about relative preferences for food safety, country-of-origin labeling and traceability. Food Policy 32:496-514. https://doi.org/10.1016/j.foodpol 2006.11.006.

Lusk, J. L. 2003. Effects of cheap talk on consumer willingness-to-pay for golden rice. Am. J. Agric. Econ. 85:840-856. https://doi.org/ 10.1111/1467-8276.00492.

Lusk, J. L., and F. B. Norwood. 2005. Effect of experimental design on choice-based conjoint valuation estimates. Am. J. Agric. Econ. 87:771-785. https://doi.org/10.1111/j.1467-8276.2005.00761.x.

Maynard, L. J., C. Wolf, and M. Gearhardt. 2005. Can futures and options markets hold the milk price safety net? Policy conflicts and market failures in dairy hedging. Rev. Agric. Econ. 27:273-286. https://doi.org/10.1111/j.1467-9353.2005.00226.x.

McKendree, M. G. S., C. C. Croney, and N. J. Olynk Widmar. 2014. Effects of demographic factors and information sources on United States consumer perceptions of animal welfare. J. Anim. Sci. 92:3161-3173. https://doi.org/10.2527/jas.2014-6874.

Morgan, C. J., C. C. Croney, and N. J. O. Widmar. 2016. Exploring relationships between ethical consumption, lifestyle choices, and social responsibility. Adv. Appl. Sociol 6:199-216. https://doi.org/ 10.4236/aasoci.2016.65017.

Morgan, S. 2017. Are Cheese Sticks Healthy. Livestrong.com. Accessed Oct. 31, 2018. https://www.livestrong.com/article/374889 -are-cheese-sticks-healthy/.

Napolitano, F., A. Braghieri, E. Piasentier, S. Favotto, S. Naspetti, and R. Zanoli. 2010. Cheese liking and consumer willingness to pay as affected by information about organic production. J. Dairy Res. 77:280-286. https://doi.org/10.1017/S0022029910000130.

Nelson, C. H. 2001. Risk perception, behavior, and consumer response to genetically modified organisms: toward understanding American and European public reaction. Am. Behav. Sci. 44:1371-1388. https://doi.org/10.1177/00027640121956737.

Nicklas, T. A., L. Jahns, M. L. Bogle, D. N. Chester, M. Giovanni, D. M. Klurfeld, K. Laugero, Y. Liu, S. Lopez, and K. L. Tucker. 2013. Barriers and facilitators for consumer adherence to the dietary guidelines for Americans: the HEALTH study. J. Acad. Nutr. Diet 113:1317-1331. https://doi.org/10.1016/j.jand.2013.05.004.

NSW. 2018. Dehorning Cattle. Department of Primary Industries. Accessed Dec. 10, 2018. https://www.dpi.nsw.gov.au/animals-and -livestock/beef-cattle/husbandry/general-management/dehorning -cattle.

O'Brien, N. M., and T. P. O'Connor. 2017. Nutritional aspects of cheese. Cheese (Fourth Edition) 603-611. https://doi.org/10 .1007/978-1-4899-7681-9_20.

Oliver, S. P., S. E. Murinda, and B. M. Jayarao. 2011. Impact of antibiotic use in adult dairy cows on antimicrobial resistance of veterinary and human pathogens: A comprehensive review. Foodborne Pathog. Dis. 8:337-355. https://doi.org/10.1089/fpd.2010.0730.

Olynk, N. J., and D. L. Ortega. 2013. Consumer preferences for verified dairy cattle management practices in processed dairy products. Food Control 30:298-305. https://doi.org/10.1016/j.foodcont 2012.07.030.

Olynk, N. J., G. T. Tonsor, and C. A. Wolf. 2010. Consumer willingness to pay for livestock credence attribute claim verification. J. Agric. Resour. Econ. 35:261-280.

Perisse, J., F. Sizaret, and P. Francois. 1969. The effect of income on the structure of the diet. FAO Nutrition Newsletter 7:1-9.

Phillips, C. J. C., J. Wojciechowska, J. Meng, and N. Cross. 2009. Perceptions of the importance of different welfare issues in livestock production. Animal 3:1152-1166. https://doi.org/10.1017/ S1751731109004479.

Reed Johnson, F., E. Lancsar, D. Marshall, V. Kilambi, A. Mühlbacher, D. A. Regier, B. W. Bresnahan, B. Kanninen, and J. F. P. Bridges. 2013. Constructing experimental designs for discretechoice experiments: Report of the ISPOR conjoint analysis ex- 
perimental design good research practices task force. Value Health 16:3-13. https://doi.org/10.1016/j.jval.2012.08.2223.

Reiter, A. 2017. Americans are scarfing down a record amount of cheese. Food Network. Accessed Oct. 30, 2018. https://www .foodnetwork.com/fn-dish/news/2017/01/americans-are-scarfing -down-a-record-amount-of-cheese.

SAS Institute Inc. 2014. SAS/QC ${ }^{\circledR} 13.2$ User's Guide. SAS Institute Inc., Cary, NC.

Sato, K., P. C. Bartlett, and M. A. Saaed. 2005. Antimicrobial susceptibility of Escherichia coli isolates from dairy farms using organic versus conventional production methods. J. Am. Vet. Med. Assoc. 226:589-594. https://doi.org/10.2460/javma.2005.226.589.

Scholliers, P. 2015. Convenience foods. What, why, and when. Appetite 94:2-6. https://doi.org/10.1016/j.appet.2015.02.017.

Schütz, K. E., A. R. Rogers, N. R. Cox, and C. B. Tucker. 2009. Dairy cows prefer shade that offers greater protection against solar radiation in summer: Shade use, behaviour, and body temperature. Appl. Anim. Behav. Sci. 116:28-34. https://doi.org/10.1016/ j.applanim.2008.07.005.

Siri-Tarino, P. W., and R. M. Krauss. 2016. Which cheese to choose? Am. J. Clin. Nutr. 104:953-954. https://doi.org/10.3945/ajcn.116 .143305 .

Spooner, J. M., C. A. Schuppli, and D. Fraser. 2014. Attitudes of Canadian citizens toward farm animal welfare: A qualitative study. Livest. Sci. 163:150-158. https://doi.org/10.1016/j.livsci.2014.02 .011 .

Tam, D. 2017. Americans are eating more cheese than ever. MarketPlace. Accessed Dec. 12, 2018. https://www.marketplace.org/ 2016/08/26/economy/americans-are-eating-more-cheese-ever.

Thompson, N. M., N. O. Widmar, M. M. Schutz, J. B. Cole, and C. A. Wolf. 2017. Economics considerations of breeding for polled dairy cows versus dehorning in the United States. J. Dairy Sci. 100:4941-4952. https://doi.org/10.3168/jds.2016-12099.

Train, K. E. 2009. Discrete Choice Methods with Simulation. Cambridge University Press, Cambridge, UK.

US Census Bureau. 2016. Annual Estimates of the Resident Population for the United States, Regions, States, and Puerto Rico: April 1, 2010 to July 1, 2015 (NST-EST2015-01). Source: US Census Bureau, Population Division. Release Date: June 2016.

USDA. 2014. Dairy 2014 Dairy Cattle Management Practices in the United States, 2014. Accessed Dec. 10, 2018. https://www .aphis.usda.gov/aphis/ourfocus/animalhealth/monitoring-and -surveillance/nahms/nahms_dairy_studies/!ut/p/z1/1ZLLUo MwFIafpQuWNie0A9QdIFNQqNoWi9kwqeU2A4RJUhl9 eu Nl46UUs8kk830nOX-CCEoQaelzVVBZsZbWav1IjHSF3SVY cxwuvSsMtr8IbnzTAIhMtPsAwtu5i50NqNlzwPbWZuR5gQ54 hsj__AffUP423q4s7AQLfZwPJ4YN4_wBgAyXvz53gEpQ55Eb FYh0VJYXVZszlLS0bER6oBV_SYU8HqpMqKuQwWL3- hdwKu31OeD9OX4Av_Me0XFRs_3n57Db_cxSrfEsz3jGp0eutk spO3GpgQZ9308Lxoo6mz6xRoO_ lJIJiZLvJOqaOI6T1zDfBNVds 7OEPZm8ASUIcTk!/\#dairy2014.

Washburn, S. P., S. L. White, J. T. Green Jr., and G. A. Benson. 2002. Reproduction, mastitis, and body condition of seasonally calved Holstein and Jersey cows in confinement or pasture systems. J. Dairy Sci. 85:105-111. https://doi.org/10.3168/jds.S0022 -0302(02)74058-7.

Widmar, N., C. Morgan, C. A. Wolf, E. Yeager, S. Dominick, and C. Croney. 2017. US resident perceptions of dairy cattle management practices. Agric. Sci. 8:645-656. https://doi.org/10.4236/as.2017 .87049 .

Wolf, C., and N. Olynk Widmar. 2014. Adoption of milk and feed forward pricing methods by dairy farmers. J. Agric. Appl. Econ. 46:527-541. https://doi.org/10.1017/S1074070800029084.

Wolf, C. A., G. T. Tonsor, M. G. S. McKendree, D. U. Thomson, and J. C. Swanson. 2016. Public and farmer perceptions of dairy cattle welfare in the United States. J. Dairy Sci. 99:5892-5903. https:// doi.org/10.3168/jds.2015-10619.

Wolf, C. A., G. T. Tonsor, and N. J. Olynk. 2011. Understanding US consumer demand for milk production attributes. J. Agric. Resour. Econ. 36:326-342.
Ziliak, S. T. 2001. Some tendencies of social welfare and the problem of interpretation. Cato J. 21:499.

\section{ORCIDS}

Courtney Bir (ํ) https://orcid.org/0000-0003-0862-8241

Nicole Olynk Widmar (ํ) https://orcid.org/0000-0002-6574-5295

Nathanael M. Thompson @ https://orcid.org/0000-0003-0987-5842

Jonathan Townsend (ㄴ) https://orcid.org/0000-0002-9705-0455

Christopher A. Wolf $\odot$ https://orcid.org/0000-0003-4181-285X

\section{APPENDIX}

The next portion of this survey presents you with hypothetical cheese purchasing scenarios that you could face in a retail store where you typically shop. The 2 products that will be presented in each scenario possess the same characteristics (e.g., similar color, brand, flavor) except for varying levels of the attributes presented below. Prices vary for each product. For each scenario, please select the 226.80-g (8-ounce) block of Cheddar cheese that you would purchase, or neither, if you would not purchase either Cheddar cheese block. For your information in interpreting alternative 226.80 $\mathrm{g}$ (8-ounce) block of Cheddar cheese:

Price refers to the cost per 226.80-g (8-ounce) block of Cheddar cheese:

- $\$ 1.49$ per oz

- $\$ 2.49$ per oz

- $\$ 3.49$ per oz

- $\$ 4.49$ per oz

- $\$ 5.49$ per oz

Pasture Access refers to the ability of dairy cattle to access grass pasture and not be confined solely to indoor production facilities:

- Required means the animal was raised on an operation certified to provide animals with access to grass pasture

- Not Required indicates that no claims regarding access to grass pasture are being made

Antibiotic Use refers to the use of antibiotics on dairy cattle where:

- Not Permitted means the animal was raised on an operation claiming to never (under any circumstances), administer antibiotics to animals

- Permitted indicates that no claims regarding use of antibiotics are being made 

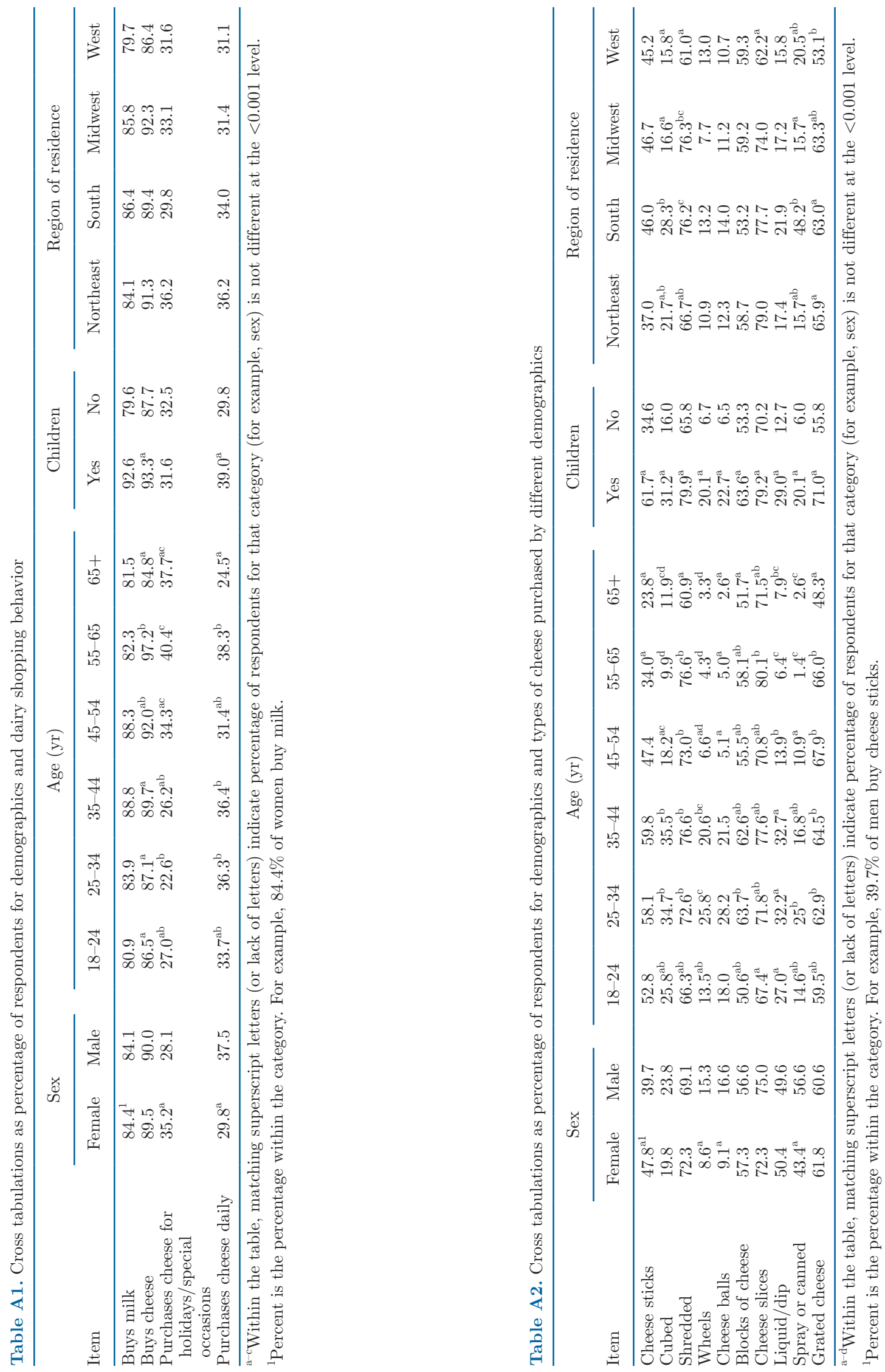
Certification Entity refers to the process used in verifying animal welfare and handling claims made on the product label where:

- USDA-process verification program means the label is backed by a producer's participation in a certification and process verification program managed by the USDA

- Dairy Industry Certification mean the label is backed by a producer's participation in a certification and verification program managed by the dairy industry itself

- Retailer Certification means the label is backed by a producer's participation in a certification and verification program managed by a private, third party retailer that is neither associated with the livestock industry nor any consumer groups

Horn removal method refers to the method used to ensure cows do not have horns

- Polled cattle are selectively bred to not have horns

- Disbudding is the removal of horn buds by way of cauterization before they have grown into horns without pain relief

- Disbudding with pain relief is the removal of horn buds by way of cauterization before they have grown into horns, with pain relief 